\title{
Free Judgment Difficulties and Solutions of Administrative Punishment Concretizing on the People's Bank of China -- Analysis Based on Legal Texts
}

\author{
Nannan Chen \\ The Oriental Institute of Shandong University of Finance and Economics, Shandong, China
}

Keywords: administrative punishment, free judgment right, legislation conflict

\begin{abstract}
Even in a civil law country, the administrative punishment existence of free judgment right is necessary. The reasons include: language has limitation for information sharing, the law predictability requires lawmakers to reserve space for the executive, elastic free judgment is the comprehensive consideration when the administrative organ executes the law, and this is the necessary condition for substantive fairness. Concretize the free judgment of administrative punishment is the necessary method of the administrative department to standardize law enforcement, set reasonable boundaries, restrain administrative power to prevent abuse and realize administration according to law. It has become a trend in recent years.
\end{abstract}

\section{Introduction}

As the administrative subject, the People's Bank of China functions involve such as maintaining financial stability, implement monetary policy, setting RMB exchange rate policy, supervise anti-money laundering, manage the state Treasury, and manage the credit reporting industry and so on 1. The financial legal system related to the People's Bank of China is mainly based on the "Law of the People's Bank of China”, "Commercial Banking Law”, “Anti-money Laundering Law” and "Negotiable Instruments Law". If it is divided according to the level of validity, it can be divided into four levels: law, administrative regulations, departmental rules and other normative documents. In the aspect of administrative punishment, "Administrative Review Law", the "Administrative Procedure Law", and "Administrative Punishments Law" are the leader. "Law Enforcement Inspection Procedure Regulations of the People's Bank of China”, and "People’s bank of China Administrative Punishment Procedures” as concrete administrative rules.

\section{Administrative Punishment Set the Discretion Benchmark}

Theoretically, the technical structure of administrative discretion is represented by the Anglo-American law and German law. There is a dispute between "monism" and "dualism". In Anglo-American law, administrative discretion is a relatively crude concept. They are inclined to include all the selective behaviors of the administrative organs in the category of administrative discretion. The question and fact of law is one. Therefore, it is not possible to construct the discretion standard by the legal provisions. "Dualism" is represented by the German law, discretion problem is only in effect discretion and legal essentials cannot be arbitrarily diversified as facts. In the law enforcement practice of administrative organs, it seems that the administrative subject does not distinguish between them strictly. We adopt more general and flexible "monism" viewpoint. The elaboration of the discretion benchmark contains not only the refinement of the plot but also the distinction of the legal effect. The author agrees with the view of "monism" that the degree of illegal behavior is not independent of its punishment.

\subsection{Discretion about quantity.}

Divide the quantity is the easiest and easiest way. The number of legal provisions can be expressed as the amount, proportion and so on. Take article 22 of the Penalties for Illegal Financial Activities (decree no. 260 of the state council) as an example: financial institutions may not hold financial deposits or funds. Any financial institution that engages in financial deposits or funds shall 
be given a warning, confiscate the illegal income and to impose a fine of more than one time and three times the illegal earnings. If there is no illegal income, there shall be a fine of not less than RMB 50,000 yuan but not more than 300,000 yuan. Senior managers who are directly responsible to the financial institution shall be removed from their posts until disciplinary action is taken. Any other directly responsible person or directly responsible person shall be demoted to a disciplinary sanction of dismissal. Combination with the practice, financial institutions have the illegal degree of financial deposit or capital. We can comprehensively measure the number of days of occupation, the number of funds and the amount of occupation, and finally determine the specific administrative penalty measures.

\subsection{Discretion of time limit.}

For example, the provision of article 80 of the "Commercial Bank Law": If a commercial bank fails to submit relevant documents or materials to the banking regulatory agency under the state council in accordance with the provisions, the banking supervision and administration department under the state council shall order it to make corrections. Whoever fails to make corrections within the time limit shall be fined not less than 100,000 yuan but not more than 300,000 yuan. The premise of the behavior here is that commercial Banks do not submit and do not correct in accordance with the regulations. And the act that after the behavior has a specified amount. The time limit here is not specified. Therefore, we can decide the amount of the referee in the case according to the time limit. Between the definition of illegal behavior and the amount of fines, we need to consider the number of overdue days, the situation of correction and other factors. Then, we can establish the correspondence between the two, and the time limit can be defined as one of the factors.

\subsection{Discretion of the plot.}

The words that commonly used in the legal provisions to describe the seriousness of the plot include: Mild, severe, severe, and especially serious. In the same law and based on the seriousness of the plot we operate the punishment from low to high. However, there has no unified standard among the different laws, which makes the use of chaos. Through the law comparison, the circumstances are the minimum punishment level. The general level of illegal action is not clearly stated in the law. However, its penalty level is substantial and secondary to serious and serious, especially to the highest level.

\subsection{Additional factors.}

There have some special discretion standards during the practice. Though the detailed laws have no specified introduction, the law effect will influence the punishment result. It can be universally applicable. For example, the social influence degree, the actor subjective state and the illegal behavior nature. The social consequences severity include the scope extent, the damage to the relative and the third party, and so on. The actor subjectivity consider the subjective and malignant behavior of the actor. The nature of the illegal behavior includes the first offense or the recidivism.

\section{The Practical Dilemma of Exercising Discretion}

\subsection{Current legislative conflict.}

The legislative conflict may cause by the legal system fragmentation and the revision need. Based on the article 77 of the "Commercial Banking Law", provide false or concealing financial statements, statements and statistical reports of important facts, the People's Bank of China shall be ordered to make corrections with not less than 200,000 yuan but not more than 500,000 yuan. According to article 38 of the "Administrative Rules for Financial Statistics", if the financial statistics are falsified or concealed, the financial institution shall be given a warning and a fine of not more than 30,000 yuan. There is a clear conflict between the two clauses in the amount of the fine. "Administrative Rules for Financial Statistics" is the legal basis of the financial statistics management regulations during the practice. It is an urgent problem to solve the discretionary 
power problem caused by legislative conflict.

\subsection{Administrative penalty measures and administrative appointment.}

Based on the current administrative punishment law, the types of administrative punishment measures include: warning; fine; confiscation of illegal income and confiscation of illegal property; order to suspend production and shutdown; suspension or revocation of the license, suspension or revocation of the license; Administrative detention; other administrative punishments prescribed by laws and administrative regulations. In the legal system of financial supervision, the administrative punishment that can be taken by the central bank is mainly include: warning, fine, confiscation of illegal income, and suspension or revocation of the permit. Fines are the most common administrative punishment. There are two types of restrictions on fines: the first is to specify the specific amount directly, and the second is to set the upper limit, lower limit or both.

Otherwise, when the administrative counterpart has illegal act, the administrative department will make appointment sometimes as the additional means, which is a warning and push the correction. There has no appointment in the administrative punishment laws. This is an unavoidable reality problem as a common method during the practice. Actually, appointment is more often referred to in the process of government governance, it is not a professional legal term. In September 2002, the local taxation bureau of Liaoning province issued the notice of "Appointment on Personal Income Tax of Foreign Nationals" (Liao Land Tax Letter [2002] NO.296). This is the first official document about the appointment. After that, this method developed in tax reform field, which demonstrated the flexibility and efficiency. This new administrative means has spread rapidly, and extend to various fields, such as environmental protection, land and resources, energy, market regulation, safety production supervision and other administrative management. In the article "Study on the Legalization of Administration Appointment", there are 178 departments of administrative regulations, including the ministerial rules, local regulations, local government regulations and other normative documents.

\subsection{Some of the discretionary standards are difficult to refine.}

From the above we can find out, there is a special kind of discretionary benchmark with universal applicability in practice, which must be combined with specific cases.

The serious degree of social consequences is different, which is difficult to materialize. It is not only the cost of resources, but also cannot have a good effect, and the administrative subject's discretion is rigid.

Most subjective malignancy of the actor (intentional or negligent) is the concept discussed in the theory of criminal law. It is closely related to the conviction and sentencing of the actor. However, most of the illegal behaviors in bank supervision are corporate bodies. There has no subjective and malignant. As additional factors beyond the specific provisions, the application of subjective states has limitations. Moreover, even if it is possible to distinguish between intentional or negligent, it is a big difficult of legislation technology to make a distinction with different law effect.

Otherwise, another important reason is the law predictability. The illegal behavior in individual articles seldom appears in practice, and it is difficult to make a hard distinction among laws based on the lack of experience.

\section{Solutions}

\subsection{Resolve the legislative conflict based on the application rule of effect precedency.}

The "Legislative Law" establishes three laws to regulate conflict resolution. They are "the rule that higher norms are superior to lower ones", "the special law is superior to the general law", and "the new law is superior to the old one". It frames the basic framework for solving the conflict of legal norms. However, there are conflicts between different conflict resolution rules. Professor Liu Zhigang believes the conflict between "the rule that higher norms are superior to lower ones" and "the special law is superior to the general law" cam solved by applying the rules of priority. The 
conflict between "the special law is superior to the general law" and "the new law is superior to the old one”, we respect the new general law, discard the adjudication, and the new general law is superior to the old law. The conflict between "the new law is better than the old one" and "Law of non- retroactivity", we follow the act is better than the rules.

The revision of new laws or old laws requires the repeal or renewal of existing regulations, departmental rules or other normative documents. The latter always has a certain lag. Therefore, it is unnecessary to set the threshold for the rules and regulations elaboration that to be eliminated.

\subsection{Use administrative appointment with caution.}

Administrative appointment is a new thing in the practice of administrative law enforcement. The application situation, exercise program, legal effect are in blank state. Based on the premise that the law and regulations has no punishment of the appointment, the writer believes we should be careful with discretion and introduce law enforcement measures. Some scholars believe that the oversimplification formation is the combination of administrative vacancy and offside. On one hand, the government tries to avoid the judicial investigation by instructing them instead of the compulsory punishment. On the other hand, there are problems of improper application and abuse of power. Combination with the setting of central bank institutions, the legal literacy of law enforcement personnel varies from region to region, level and specialty. We should adopt a conservative attitude when refining the discretionary standard.

\subsection{Avoid setting a single standard.}

In the elaboration of administrative punishment discretion, it is necessary to avoid setting a single standard of administrative punishment. We need to consider various factors of setting discretionary benchmarks. It is not conducive to the discretion exercise if we only consider the factors which may be involved in the specific legal provisions. "Credit Reporting Industry Regulations" is an example. Based on article 38, paragraph 1, if credit agency, financial credit information basic database operation institution violates the rules to steal or illegally obtaining information in other ways, the supervision and administration department of the state council's credit investigation department or its dispatch agency shall order the rectification within a time limit. Moreover, it will operate a fine of more than 50,000 yuan and less than 500,000 yuan per unit. If we divide the illegal act based on the information number, the maximum penalty is a fine of 500,000 yuan, and other additional factors, such as the adverse social impact of the illegal act, cannot be reflected in the punishment results.

The discretion exercise is a complex process with individual differences. Rigid division can only lead discretionary power petrification. Therefore, not all scholars have voted the trend of refining the discretionary standards of administrative punishment. At the current situation, the author believes that at least through the above approaches, we can set a basic limit for the discretion, so as to achieve the positive effect.

\section{References}

[1] Hua Anqing, Standard Exercise of Administrative Discretion, Modern Bankers, 2015, 12, p.138-139

[2] Yang Fagen, Yu Ying, Specification Discussion of Administrative Discretion about People's Bank of China, Journal of Finance and Economics, 2012,4, p.78-81

[3] Huang Shixuan, Legal Recourse of Administrative Discretion, Journal of Liaoning Institute of Science and Technology, 2015, 2, p.34-35

[4] Sheng Xiaoli, Limitation Discussion of Administrative Discretion, Journal of Jingdezhen University, 2013, 3, p.123-124 